\title{
Establishment on Index System for Process Evaluation of Flipped Classroom
}

\author{
Ping Zhao \\ Baicheng Normal University, Baicheng, 137000, China \\ 50229822@QQ.COM
}

Keywords: Flipped classroom, Teaching model, Process evaluation, Index system.

\begin{abstract}
Many colleges and universities promote the use of flipped classroom teaching model, change the traditional inculcation of teaching in the past. Teaching evaluation is the value judgment on the process and resources of teaching and learning, and it can provide reliable basis for teachers' teaching and students' learning. Compared with the traditional evaluation is only concerned with the teaching effect, the process evaluation has the characteristics of the evaluation content diversification, the evaluation standard materialization, the evaluation subject diversification and the equalization of the evaluation relationship. Based on the teaching process of flipped classroom, this paper follows the establishment principle of the evaluation index system, constructs the index system structural model for process evaluation of flipped classroom teaching, and gives a brief description of the evaluation index. The research results of this paper play an important role in improving the teaching effect of flipped classroom and cultivating students' autonomous learning ability.
\end{abstract}

\section{Introduction}

The flipped classroom teaching model is based on information technology, so that students in the pre-class to complete the knowledge learning, teachers provide students with collaborative learning and exchanging opportunities to help students achieve the internalization of knowledge, so that students become the master of learning. Flipped classroom teaching model reorient the allocation of time inside and outside the classroom, and transfer the learning decision from teachers to students, the main part of study is students, teachers become the designers, mentors, helpers and learning partners for students. The flipped classroom teaching model embodies the advantages of "mixing learning", which conforms to the cognitive rules of human beings and helps to construct the new type of teacher-student relationship, which can promote the effective use of teaching resources and have revolutionary meaning to the development of education, and also bring a lot of challenges. It plays an important role in promoting teacher's dominance student's subjectivity and improving teaching and learning.

Teaching evaluation is based on the teaching objectives, use scientific and feasible methods, give value judgment to teaching and learning process, and provide reliable basis to promote teachers' teaching and students learning. Teaching evaluation generally includes the evaluation of teachers, students, teaching contents, teaching methods, teaching environment and teaching management in the process of teaching, but the mainly evaluation is the teaching process of teachers' learning effect. Teaching evaluation has diagnostic effect to determine teaching quality, level, effectiveness and shortcomings, which is a rigorous scientific diagnosis of teaching; teaching evaluation has stimulating effect, which can effectively promote classroom learning; teaching evaluation has regulatory effect, teachers and students can adjust the teaching behavior according to the feedback revision plan.

The process evaluation compare with the traditional summative evaluation, which has the characteristics of evaluation content diversification, evaluation standardization, evaluation subject diversification and equalization of evaluation relationship. Process evaluation takes both the goal 
and the process of value orientation, the teaching effect and process, and learning closely related to the non-intellectual factors to conduct comprehensive evaluation. Advocate the combination of internal-external union and open evaluation, evaluation process and the teaching process of cross integration, evaluation of the main body and object interaction integration. Through the quality of teaching to make judgments, affirmative results, identify problems, and promote students to study the process of positive reflection, so as to better grasp the learning method. The establishment of the index system is the basic work of the system evaluation. In this paper, the evaluation index system is established for the education process and characteristics of the classroom, and the effect of the teaching model is improved.

\section{Teaching Process of Flipped Classroom}

The teaching model in the flipped classroom is mainly composed of in class and after school two stages: the teachers' activities and the students' activities. The whole teaching process is divided into five stages: "Resource development, Study before class, Classroom teaching, Consolidate after class and Discussion and summary", as shown in Fig.1.

\begin{tabular}{|c|c|c|c|c|}
\hline $\begin{array}{c}\text { Resource } \\
\text { development }\end{array}$ & $\begin{array}{c}\text { Study before } \\
\text { class }\end{array}$ & $\begin{array}{c}\text { Classroom } \\
\text { teaching }\end{array}$ & $\begin{array}{c}\text { Consolidate } \\
\text { after class }\end{array}$ & $\begin{array}{c}\text { Discussion } \\
\text { and summary }\end{array}$ \\
\hline
\end{tabular}

Fig .1. Teaching process of flipped classroom

(1) Resource development, which is developed or collected by the teacher, can be micro-course-based learning resources, can be PPT type, lectures or scenarios and other types of drama, it can be electronic lesson plans, electronic teaching materials, audio and video data and other learning resources.

(2) Study before class. This is an "assimilation" process, students use the existing cognitive structure of the new knowledge to transform, integrated into the original cognitive structure of the model, so that cognitive structure is rich and expanded.

(3) Classroom teaching. The process of knowledge internalization, students through knowledge exchange and knowledge sharing, absorb and understand new knowledge, format new cognitive structure. Teachers explain for key issues and key knowledge points, provide personalized guidance.

(4) Consolidate after class. Use variety of means to consolidate the knowledge. This is a "conforming" process in which new knowledge cannot be accommodated in the original cognitive structure and is not closely related to the original cognitive structure and requires the renewal or reconstruction of the cognitive structure.

(5) Discussion and summary. Teachers need to reflect on the shortcomings of education and teaching activities, and constantly correct the teaching ideas and behavior, and then explore the new realm, achieve the common development of teachers and students, which is the ultimate goal of teaching.

\section{Establishment Principles of Evaluation Index System}

The evaluation principle is the principle, criteria and requirements that must be followed in the evaluation activities. According to the characteristics of the evaluation of the nature of the rules and flip the characteristics of classroom teaching model, with reference to other relevant references, the construction of evaluation index system should follow the following principles:

(1) The principle of the unity of integrity and objectivity. The overall integrity requirements of the evaluation indicators include teachers and students in the teaching activities of the performance, while the system can reflect the individual and the overall evaluation results. Objectivity principle is the use of evaluation indicators, the objective of the teaching process to make an evaluation, that indicators can reflect the overall development of the situation. There is a necessary and necessary relationship between the upper and lower indicators, and the underlying indicators are the concrete 
indicators of the upper indicators, which reflect the objectives and requirements required by the upper targets.

(2) The principle of combining advanced concepts with realistic conditions. The evaluation system of the indicators to reflect the flip classroom teaching model of ideas, ideas and principles, reflecting the independent learning activities and information age teaching new requirements. The advanced nature of the evaluation index should be realistic and objective. Indicators are set too high, difficult to achieve, can not be understood by most teachers, will lose the incentive effect; indicators set too low, they will lose the advanced nature of indicators and guidance, teaching does not have a role in promoting.

(3) The principle of simplicity and guidance. Teaching evaluation is a very practical work, the composition of the evaluation system has a strong practicality. Indicators should be simple, easy to master and use. Open, fair and practical evaluation system is not only the basis for evaluation of teaching, but also constantly changing teaching ideas, improve teaching methods and improve the quality of classroom teaching a direct reference. However, too simple index system may be easy to grasp and operation, but not conducive to the teaching of the guidance.

(4) Qualitative analysis and quantitative analysis of the principle of combining. The combination of the two is determined by the unity and complementarity between the two. Qualitative analysis is the basic premise of quantitative analysis, there is no qualitative quantitative is blind, worthless quantitative; quantitative analysis to make it more scientific and accurate qualitative analysis to lead to extensive and in-depth conclusions. The two complement each other, qualitative is the basis of quantitative, quantitative is the qualitative of the specific combination of the two can be used in order to achieve the best results.

\section{Structure Model of Evaluation Index System}

The general method of constructing the index system is to summarize the collected data, and then measure it according to the scale. It is necessary to use the method of logical reasoning and the fact that the subjective and objective factors are combined and analyzed. Flipped classroom as new teaching model, its specialized research literature less, there is no uniform flipped teaching system evaluation index system. The evaluation index system is established. The actual problem is decomposed into several factors. The factors are divided into several groups according to different attributes. The hierarchical structure can be divided into the highest level, the middle level and the bottom level. The middle level is also known as the standard level, that the middle part of the overall goal, according to the size of the problem and the complexity of the level can be many levels; the bottom level is also known as the program level, indicates the measures, decisions, or options to be used to achieve the goal. According to the related literature, this paper constructs the structural evaluation model for the process evaluation index of the flipped classroom teaching as shown in Fig.2.

\section{Brief Description of Evaluation Index System}

The first-level indicators included in the evaluation index structural model shown in Fig.2 are briefly described as follows:

(1) Teaching resources. Resources design is based on the teaching theory and the characteristics of learners, the organization of teaching content and teaching resources, the design of teaching activities and learning environment, support learners to achieve effective learning objectives. In the whole teaching process, the teaching resources directly affect the teaching effect and even the success or failure of teaching, so the careful design of teaching resources and teaching content of the reasonable arrangement, especially in the flipped teaching are very important. Teaching resources are designed to: language accurate, lively, structured, both for the whole, but also concerned about individual differences, make full use of information technology advantages of effective control of teaching activities. 
(2) Teaching design. Teaching design is based on systematic method, transfer the teaching principles into teaching materials and teaching activities of the programs and programs to achieve the teaching objectives of the planning and decisional activities to help learners access to knowledge, skills and interests, iincluding teaching content, steps and time allocation. Flipped classroom teaching design follow the principles of self-learning, teachers, individual guidance, diverse choice of resources, active activities, effective classroom interaction, focus on capacity-building, learning evaluation and other principles. Teaching design should be consistent with the actual situation of students and syllabus, correctly put forward key difficulties, and seize the key knowledge points.

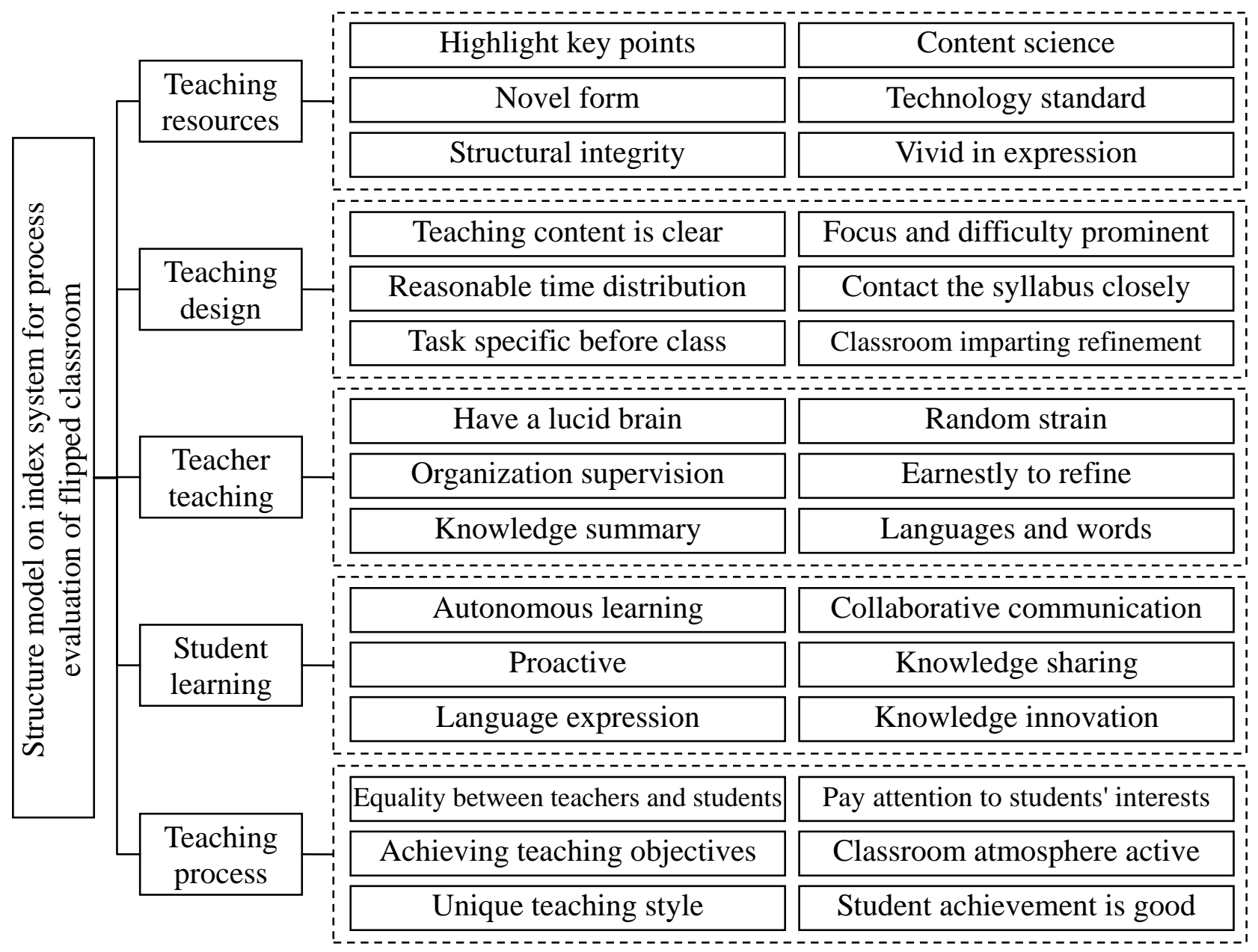

Fig.2. Structure model on index system for process evaluation of flipped classroom

(3) Teacher teaching. Flipped classroom teaching, achieve the teacher 's role in the three changes from the course of the implementation of the executor to the developer, by the control of the activities of planners to director, from the knowledge of the authority to the collaborators. Teachers become scaffolding for students to obtain resources, use resources, information processing and application knowledge in the classroom to reduce the teacher teaching time, leaving the students more time to learn activities, without reducing the basic knowledge on the basis of display, and increase iinteractivity of students. In order to improve the quality of teaching, strengthen the quality of teachers training, the formation of a strong teaching and research team.

(4) Student learning. Student learning is the key factor in the smooth implementation of the classroom, to improve the students' consciousness of learning, complete the team to explore cooperation. Create applied questions, guide students find knowledge by themselves; create interesting questions, raise students' interest in learning independently; create open questions and guide students to think positively; create new suspense, guide students to explore their own; create puzzled trap, guide students to take the initiative to create students with the initiative to explore the students; participate in the discussion; create sequence of existing knowledge to guide students to 
obtain new knowledge of the growth point. Make full use of innovative courses and innovative teachers and other resources, improve innovation and innovation quality.

(5) Teaching process. Teaching process refers to the process of teaching activities, is based on the social requirements of teachers and students physical and mental development characteristics, with certain teaching conditions, guide students through the understanding of teaching content to understand the objective world, and on this basis to develop their own process. Compared with the traditional model teaching, the translation classroom mixes the direct explanation and constructivism learning, the teaching process has changed fundamentally, increases the interaction between the student and the teacher and the individual contact time, the teacher should pay attention to the student interest, the active classroom atmosphere, let students accept personalized education, and continuously improve the students' academic performance and practical application ability.

\section{Conclusion}

Process evaluation includes three aspects: one refers to the teaching process, teaching is the process of teachers, students and teaching content of the interaction process; the second refers to the learning process, different students in the process of learning will be different The way of learning, and different learning methods will lead to different learning results; three refers to the evaluation process, teachers collect relevant information, information analysis and judgment, obtain relatively objective evaluation results. The process evaluation has the characteristics of diversifying the evaluation content, the specificity of the evaluation criteria, the diversification of the evaluation subject and the equalization of the evaluation relationship, covering the whole process of teaching and learning, and truly reflecting the teaching effect of the flipped classroom. Scientific flipped classroom evaluation system, can improve the enthusiasm of teachers, promote students' enthusiasm for learning, change the passive learning to take the initiative to learn. The establishment of evaluation indicators is the complex work, this study is a new attempt in the field of teaching evaluation. Any scientific evaluation of the index system is a hard job. Although the study accepts standardized research methods, but due to limited research conditions, the scientific nature of the index system has not been further testing yet.

\section{References}

[1] J. Zhang, "Design of learning evaluation in flipped classroom," Journal of Curriculum and Instruction, vol. 4, no. 11, pp. 24-27, 2015.

[2] Z. H. Wang, "Classroom evaluation criteria under the flipped classroom teaching model," Testing and Evaluation, vol. 24, no. 5, pp. 94-95, 2017.

[3] L. O. Yin, H. Yan, "The application of process assessment in Comprehensive English Teaching," knowledge economy, vol. 17, no. 5, pp. 152-153, 2017.

[4] J. L. Zhang, Y. Wang, B. H. Zhang, "Research on flipped classroom teaching mode," Journal of Distance Education, vol. 30, no. 4, pp. 46-51, 2012.

[5] Ramazan Yilmaz. Exploring the role of e-learning readiness on student satisfaction and motivation in flipped classroom[J]. Computers in Human Behavior, 2017, 70(5): 251-260.

[6] J. Zhang, "Establishment on indicator system for process evaluation of rotating classroom," Journal of Bohai University (Natural Science Edition), vol. 38, no. 2, pp. 187-192, 2017.

[7] K. K. He, "The essence of 'flipped classroom' and the future development of 'flipped classroom' in our country," E-education Research, vol. 35, no. 7, 5-16, 2014. 